\title{
State Monitoring of Polymer Composites with Glass Optical Fibre and with Equipment Used in Telecommunication
}

\author{
Gergely HEGEDÜS, ${ }^{1}$ Tibor $^{1}$ CZIGÁNY ${ }^{1,2^{*}}$ \\ ${ }^{1}$ Budapest University of Technology and Economics, Faculty of Mechanical Engineering, Department of \\ Polymer Engineering, Budapest, Hungary \\ ${ }^{2}$ MTA-BME Research Group for Composite Science and Technology, Budapest, Hungary \\ * Corresponding author: czigany@eik.bme.hu
}

\begin{abstract}
Thanks to the widespread use of optical fibers in telecommunication, they, and their accompanying equipment have become cost-effective and easily accessible. We have proved that the changed attenuation of a monomodal optical fiber built into a polymer composite can indicate the elongation of the structure compared to its original, unloaded state, before the optical fiber breaks. We also proved that the location of deformation in polymer composite structures can be found with OTDR equipment (used for checking the coupling of optical fibers).
\end{abstract}

Keywords: polymer composite, deformation monitoring, optical fiber, attenuation meter, OTDR.

\section{Introduction}

Due to the continuous development of polymer composites, the need to know their material behavior is becoming increasingly important. Because of their complex structure, the simulation of their behavior $[1,2]$ is a complex task that has to take into account the different structural levels of composites, from the nanoscale material components, through the connection of the micro-level constituents (fiber, matrix) to the macro-level component (layers). For this reason, it is important to monitor the structural health of composites with non-destructive, in-situ physical methods [3]. Their complex structure allows the integration of health monitoring sensors, which greatly increases their competitiveness against other structural materials [4]. With built-in optical sensors, it is possible to monitor deformation, stresses, and the resulting damage and defects during the entire life of the composite (lamination, crosslinking, removal from the mold, assembly, use). Some characteristics of the light (power, phase, polarization, wavelength, timing, and spectral distribution) propagated in the optical fiber of the optical sensors change as a result of external conditions (such as load on the fiber, deformation) [5]. Common to the different types of optical sensors is that the signal-processing device can be detached from the optical fiber. It is a separate unit; it does not need to be built into the composite [6]. The use of optical sensors is becoming more and more common in laboratories but has not become widespread in cost-sensitive industries (e.g., the automotive industry) because it requires the installation of a relatively complex, expensive system.

An optical fiber is often used to transmit the signal between optical sensors and the processing unit. Nowadays, optical fibers and related telecommunications equipment have become readily available. The most common tool for examining the condition of joints (connections, welds) used in optical networks in telecommunications is the optical power meter. An optical power meter set consists of a light source of specific wavelength (most commonly 1310 and $1550 \mathrm{~nm}$ ), which can be connected to one end of the optical network, and a power meter unit, which can be connected to the other end of the network. Attenuation $(\alpha(\lambda)[d B])$ is the ratio of the radiated power input $\left(P_{\text {in }}\right)$ and the output $\left(P_{\text {out }}\right)$ of the fiber expressed in decibels [7] (1): 


$$
\alpha(\lambda)=10 \cdot \lg \left(P_{\text {in }} / P_{\text {out }}\right)
$$

The radiated power required to calculate the attenuation is the power (watts) emitted, transmitted, or received in the form of radiation [8]. Another common tool used to test optical networks is optical time-domain reflectometry (OTDR), which uses reflected light due to Rayleigh scattering. Rayleigh scattering is caused by the micro-anomalies in the optical fiber. As a result of the anomalies, some of the light energy in the fiber is scattered in all directions. The closer the wavelength of the light to the magnitude of the micro-defects is, the greater the degree of scattering. The part of the scattered light that arrives at the cladding of the optical fiber at an angle greater than the critical angle is reflected from it and can even travel backward within the fiber. By measuring the backscattered light, information can be obtained about the inhomogeneities of the fiber, or even about the change of the inhomogeneities. The OTDR sends a pulse of light into the fiber and monitors the light returning from it. The return signal weakens over time as the light travels longer and longer. With the use of the speed of light in the fiber, the starting point of the return signal can be calculated. Rayleigh scattering can be used to localize fiber welds, micro bends, joints, fiber defects, cracks, breaks, and branches within the optical network. With the help of the OTDR, the location of each defect on the optical fiber can be determined with an accuracy of the order of meters [9]. The advantage of the test is that it can be performed from one end of the optical fiber since the instrument measures the pulses reflected from the optical fiber.

Several researchers have shown that microlevel and macro-level bending of optical fibers is reflected in the power of light transmitted through the fiber [10-12]. Several authors have examined the condition of the composite structure with built-in optical fibers, and their results suggest that the decrease in light output at the end of the optical fiber can be used to detect damage [13-15]. This method is suitable for determining the location of the damage, but it does not provide information about its extent.

In our previous papers [16, 17] we investigated the applicability of glass optical fiber to detect the deformation of polymer composites. In this study, we continued to examine the applicability of optical fibers and the devices used in telecommunications for the health monitoring of polymer com- posite structures. Our aim was to deduce - from the changed characteristic of the light propagating in the built-in optical fiber - the change of the composite compared to its initial, unloaded state, due to repeated load. We measured the change in the attenuation of the built-in optical fiber using instruments commonly used in telecommunications (optical power meter and OTDR) during low cycle tensile loading of the composite specimen. Our goal was to detect the deformation before the critical condition causes failure, and to develop our method further. Our aim was to show that if the increase in fiber attenuation is greater than allowed, i.e., if the optical fiber is damaged somewhere because the polymer composite is damaged, an externally connected OTDR instrument common in telecommunications can be used to find the defect.

\section{Materials and equipments used}

The optical fiber used in the experiments was G.652.D single-mode glass optical fiber with an outer diameter of $125 \mu \mathrm{m}$ and a core diameter of $9 \mu \mathrm{m}$ (manufactured by Corning) with a perpendicular fiber end design.

We made the composite specimens from two layers of zero and ninety degrees woven (orthotropic) prestressed glass fabric $\left(300 \pm 5 \% \mathrm{~g} / \mathrm{m}^{2}\right.$, RT $300 \mathrm{~N}$, Kelteks). Between the two layers, we threaded a $140 \mathrm{~mm}$ long section of the $3 \mathrm{~m}$ long optical fiber. The optical fiber was guided out of the specimen in front of the grips of the tensile machine so that the grips did not directly load the optical fiber.

The optical fiber proved to be very vulnerable at the exit and entry points of the composite because after manual lamination, the resin surrounding the fiber area made the fiber very stiff and rigid. To avoid fiber breakage, we only removed the $250 \mu \mathrm{m}$ lacquer layer of the fiber (for mechanical protection) in the middle of the threaded fiber over a $100 \mathrm{~mm}$ section, leaving a $20 \mathrm{~mm}$ lacquered section on each side of the built-in fiber. The specimen was reinforced with additional reinforcing fabric as a clamping tab beyond the built-in optical fiber section (beyond $140 \mathrm{~mm}$ ). The specimens were not produced independently but were laminated by hand as a single sheet (so that during manual lamination, the fabric layers could be prestressed and would not be creased by the matrix material). Unsaturated polyester resin (AROPOL M105 TB, Ashland SpA) and $1.5 \%$ initiator (PROMOX P200TX, PROMOX SRL) were used as matrix material. After curing at room tempera- 
ture for 24 hours, the specimens were cut from the laminated sheet. The specimens were $25 \mathrm{~mm}$ wide, $1.3 \mathrm{~mm}$ thick, with a total length of $250 \mathrm{~mm}$. Clamping length was $195 \mathrm{~mm}$, and the installed length of the optical fiber was $140 \mathrm{~mm}$. Three specimens were prepared for each test.

We used a fiber breaker (Fujikura, CT-30) and a fiber welding machine (Fujikura, FSM 12 S) to splice the optical fiber. We connected light with a wavelength of $1550 \mathrm{~nm}$ (AFL Telecommunications, from a FlexScan FS-200 light source) at one end of the optical fiber. We examined the change in attenuation at the other end of the fiber with an optical power meter and OTDR instrument with a resolution of $0.01 \mathrm{~dB}$ (AFL Telecommunications, FLX380-304 FlexTester OTDR).

We loaded the composite specimens with the built-in optical fiber in a tensile machine (Zwick, BZ050 / TH3A), and the strain was calculated from the crosshead displacement (as a quotient of the crosshead displacement and the initial clamping length). The optical power meter does not have a data logger, but the display shows the current attenuation value. To assign these values to the measured displacement and force, the values displayed by the tensile machine software and the display of the optical power meter were recorded on video (Figure 1.). With the help of these recordings, the attenuation values could later be assigned to the values recorded by the tensile machine.

\section{Results and discussion}

\subsection{Effect of cyclic tensile load}

We examined the change in the attenuation of the built-in optical fiber on 3 specimens during cyclic tensile loading starting from zero load. The attenuation of the optical fibers built in the specimens after gripping was nearly $0 \mathrm{~dB}$. In the tests, the loading and unloading speeds were set to be $1.5 \mathrm{~mm} / \mathrm{min}$ with an increasing max. displacement of $0.1 \mathrm{~mm}$ per cycle. In the case of one specimen, the measured values are shown in Figure 2 and 3.

Our results show that the change in the strain and attenuation of the optical fiber can be related, which can be described by a quadratic function with a coefficient of determination greater than $94 \%$ (indicated by the dashed line in Figure 3.) This indicates that the measurement of the altered attenuation is suitable for the detection of strain.

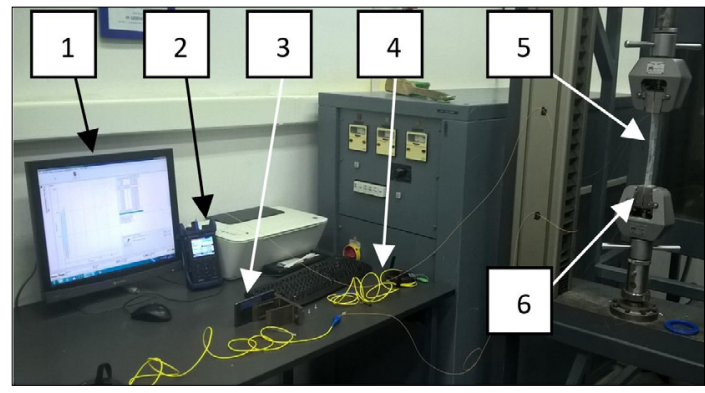

Figure 1. Measurement layout (1-measured displacement and force values, 2-optical power meter, 3-video camera, 4-optical fiber, 5-composite specimen, 6-tensile test machine gripper).

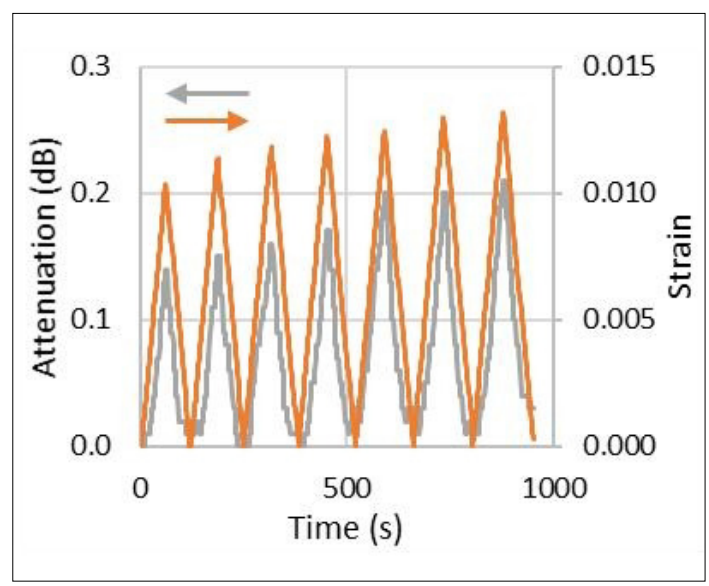

Figure 2. The change of attenuation and strain as a function of time during cyclic tensile loading.

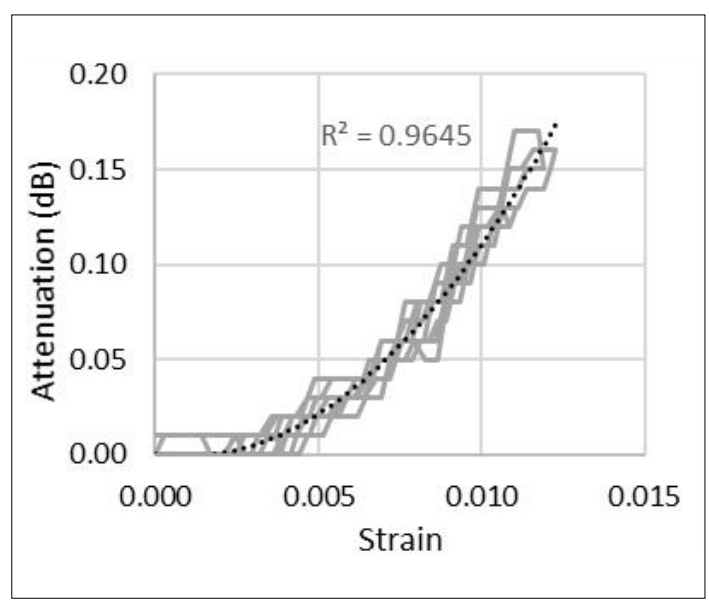

Figure 3. Attenuation of the optical fiber as a function of strain during cyclic tensile load. 
Figure 4 summarizes the change in attenuation as a function of strain.

The measurement results show that the attenuation of the optical fiber is closely related to its strain. Higher strain results in higher attenuation. Although the measured attenuation values have a large variance, it can be said that above $1 \%$ strain, the change in the attenuation of the optical fiber is greater than $0.1 \mathrm{~dB}$. This method does not allow accurate strain measurement, but with the help of the changed attenuation of the fiber, the deformation state of the composite element can be categorized: below $0.1 \mathrm{~dB}$ attenuation change, the composite is in good condition, while above $0.1 \mathrm{~dB}$ attenuation change, it is expedient to test the condition of the composite with additional methods.

In previous tests, a $140 \mathrm{~mm}$ long fiber section was built into the specimens and (ideally) the installed section was fully loaded. In our next series of experiments, we investigated the effect of more than one loaded section of the optical fiber.

\subsection{The effect of cyclic tensile load on more than one loaded section of the optical fiber}

To examine several loaded sections of the optical fiber, we clamped 2 specimens side by side in the tensile machine and pulled the specimens together (in a similar layout as shown in Figure 9.). The optical fibers built into the loaded specimens were welded together with a $10 \mathrm{~m}$ long optical fiber (the specimens were connected together with $1,5+1,5+10=13 \mathrm{~m}$ unloaded optical fibers). With this layout, we were able to load a built-in optical fiber at several points. The length of the loaded optical fiber was $2 \times 140 \mathrm{~mm}$. Loading and unloading were performed in the same way as in the previous series of experiments, at a speed of $1.5 \mathrm{~mm} / \mathrm{min}$, with an increasing maximum displacement of $0.2 \mathrm{~mm}$ per cycle. The test was stopped during the $5^{\text {th }}$ cycle and the OTDR was used instead of the optical power meter (the result of this test is presented in Chapter 3.4.). After the test was performed with the OTDR, the optical power meter was reconnected to the optical fiber and the test was continued. In cycle 7, the built-in optical fiber was torn and the optical power meter showed an attenuation of over $40 \mathrm{~dB}$. At this time, the OTDR was reconnected to it (see Chapter 3.4.). The torn optical fiber was illuminated with visible light, too. The results are presented in Chapter 3.3. Figures 5 and 6 show the test results. The attenuation measured during the test as a function of strain is shown in Figure 7.

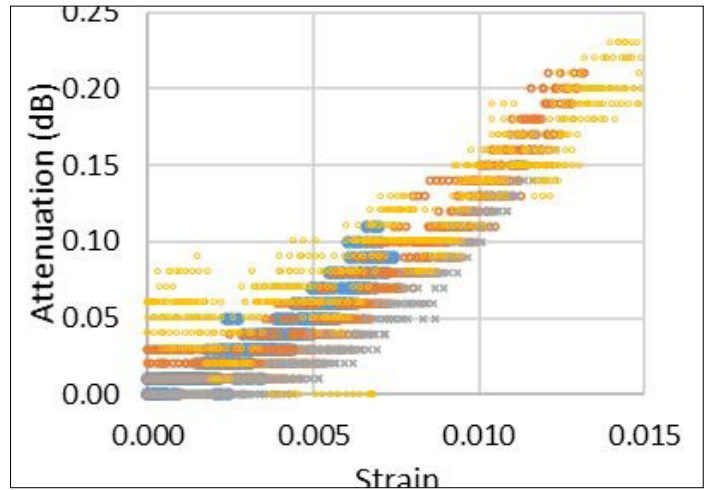

Figure 4. Attenuation measured during cyclic tensile loading as a function of strain (values measured for different specimens are marked with different colors).

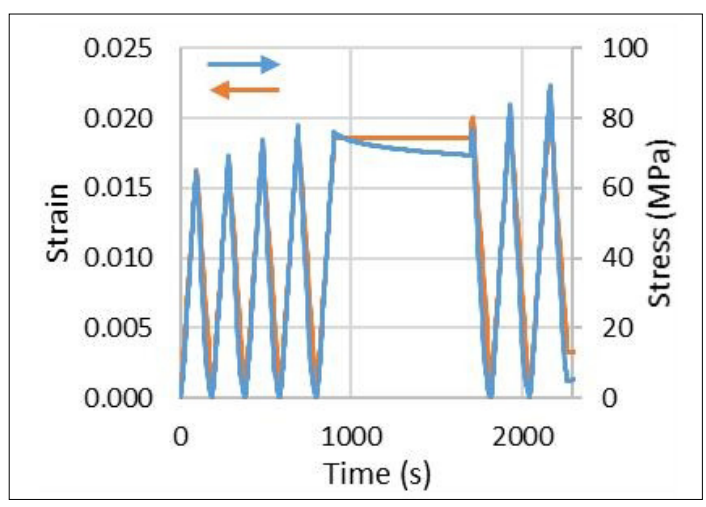

Figure 5. Strain and stress as a function of time measured during the testing of a built-in optical fiber loaded on a $2 \times 140 \mathrm{~mm}$ long section (stopping the test for testing with the OTDR is identifiable in the figure).

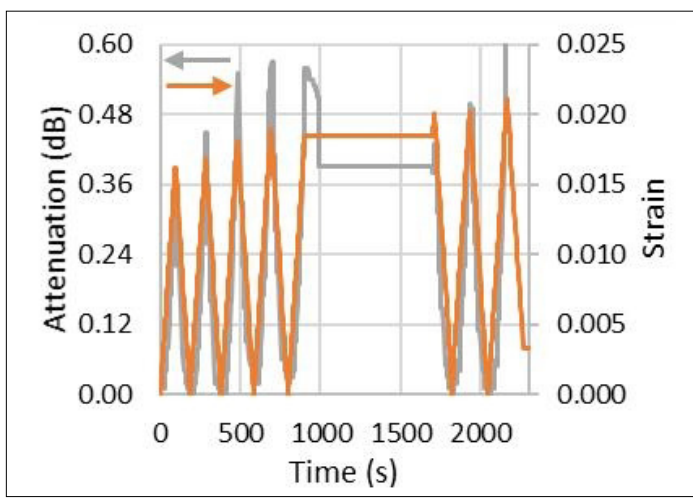

Figure 6. Attenuation and strain as a function of time measured during the testing of a built-in optical fiber loaded on a $2 \times 140 \mathrm{~mm}$ long section (stopping the test for testing with the OTDR is clearly identifiable in the figure). 


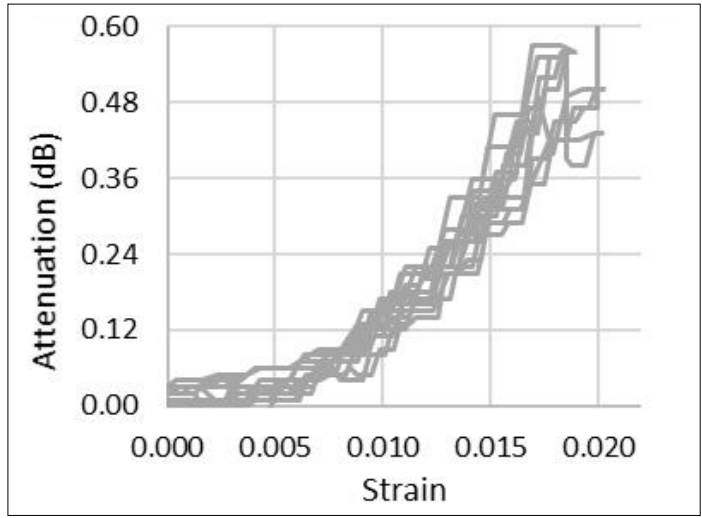

Figure 7. Change of the attenuation of the built-in optical fiber loaded at $2 \times 140 \mathrm{~mm}$ as a function of strain.

The attenuation change of the optical fiber as a function of strain is bigger than observed in the previous series of experiments, which is clearly due to the greater length of the loaded fiber section. The optical power meter detects the amount of change in attenuation on both $140 \mathrm{~mm}$ loaded sections of the optical fiber.

The results show that the length of the loaded fiber section must be known so that the deformation state of the tested composite part can be determined based on the attenuation change of the optical fiber. If an optical fiber is loaded in several places, the magnitude of the loads cannot be deduced separately with the optical power meter. If a large deformation in the vicinity of the optical fiber breaks the fiber, it can be detected with the optical power meter, but other additional tests are needed to determine the location of the failure, which will be examined below.

\subsection{Determining the location of the large de- formation using visible light}

Experiments with the optical power meter show that the attenuation of the built-in optical fibers changes as a result of the strain of the composite. The light attached to the fiber is absorbed and scattered due to the strain of the fiber. When the composite specimen is highly elongated, the optical fiber may be broken. In the event of a fracture of the fiber, light exits the fiber at the point of failure. The illumination wavelength of the optical power meter falls in the infrared radiation range, which is not visible. The exit of visible light from the fiber at the point of fracture can be identified, a phenomenon that may be suitable for locating the damage (Figure 8.).

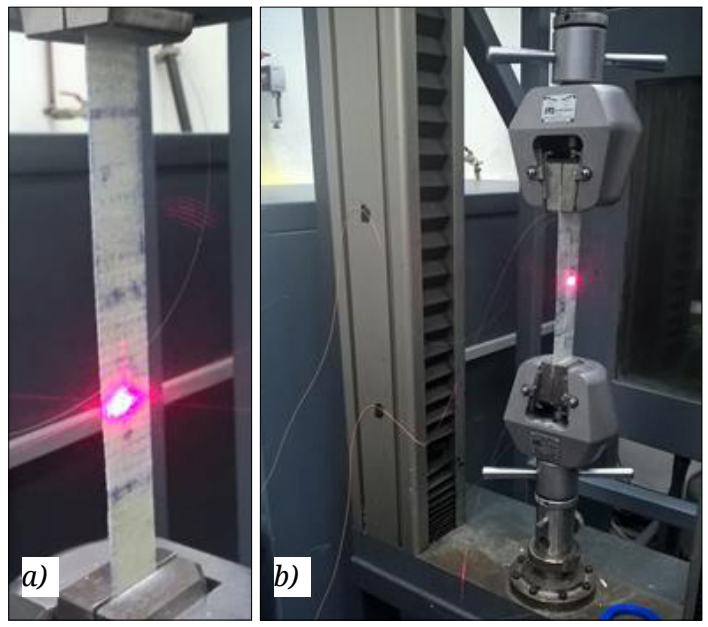

Figure 8. Visible light emitted at the point of fracture in the case of one (a) and two (b) gripped specimens.

\subsection{Determining the location of the large de- formation using OTDR}

The results so far indicate that the deformation of the environment of the optical fiber results in a change in the attenuation of the fiber. We aimed to investigate whether the location of the large deformation in the composite structure can be detected with the help of an OTDR, which is also used in the inspection of telecommunication networks. Widespread commercial OTDR instruments for testing telecommunication networks are not suitable for continuous monitoring, as it takes a relatively long time to analyze and evaluate the measured parameters. The method is not ideal for fast, in-situ condition monitoring (evaluation is in the order of minutes), but may be a suitable complement to the previously presented attenuation measurement in a periodic condition check. By examining the built-in optical fiber, the method may be suitable for detecting large deformations of the composite in the vicinity of the optical fiber and for determining the location of the deformation. To prove this theory, we stopped the movement of the crosshead of the tensile test machine under tensile load (Chapter 3.1) when the optical power meter showed a significant jump in the attenuation of the built-in optical fiber (above $1 \mathrm{~dB}$, which indicates a strain of more than $0.8 \%$ in each case). We detached the end of the optical fiber from the optical power meter and reconnected it to the OTDR using the measurement layout shown in Figure 9. 
Due to the dead zone of the OTDR, a $150 \mathrm{~m}$ optical fiber was connected after the instrument, and the optical fiber built into the composite specimen was attached to it with an optical connector. We connected an optical fiber approximately $200 \mathrm{~m}$ long to the other end of the built-in optical fiber, to avoid the reflections from the end of the fiber, followed by an additional $100 \mathrm{~m}$ long optical fiber wound with a small radius. With the OTDR, we examined the attenuation along the length of the built-in optical fiber at $1310 \mathrm{~nm}$ and $1550 \mathrm{~nm}$. The OTDR can identify the location and value of each jump in attenuation with an accuracy of $0.1 \mathrm{~m}$ and $0.01 \mathrm{~dB}$. The evaluation software tries to identify these jumps with the types of equipment and failures that occur in the optical networks. These elements cannot be interpreted in the examination of composites, but the location and value of the longitudinal attenuation change can be easily observed. The attenuation and distance measured with the OTDR on the unloaded specimen are shown in Figure 9.

The tensile test of the specimen shown in Section 3.1. was stopped at an attenuation value of $\sim 20 \mathrm{~dB}$, and the OTDR was connected as described above. The measured values are shown in Figure 10 and 11.
From the graph obtained from the measurement, it can be seen that between the two optical connectors (marked with numbers 2 and 3 at the bottom of Figure 11.) of the built-in optical fiber, the OTDR measured a considerable increase in attenuation. This increase is due to the load of the composite specimen into which the optical fiber is built. The OTDR instrument measured an attenuation of $15.2 \mathrm{~dB}$ at $1310 \mathrm{~nm}$ and $12.8 \mathrm{~dB}$ at $1550 \mathrm{~nm}$ at the fiber length of $150.7 \mathrm{~m}$. Contrary to expectations, the attenuation change in the specimen caused by the tensile load is not separated in the graph from the protrusion caused by the optical connector, which shows the disadvantage of measurement with an OTDR. The OTDR cannot detect the location the deformation causing a large attenuation change with an accuracy of $\mathrm{cm}$.

We also gripped and pulled two specimens together to observe the behavior of the multi-point loaded optical fiber and the possibility of examining it with OTDR. Two optical fibers built into the loaded specimens were welded together with a $10 \mathrm{~m}$ long optical fiber (the specimens were connected with $1.5 \mathrm{~m}+1.5 \mathrm{~m}+10 \mathrm{~m}=13 \mathrm{~m}$ unloaded optical fibers). The measurement layout and the results are shown in Figure 12, 13 and 14.

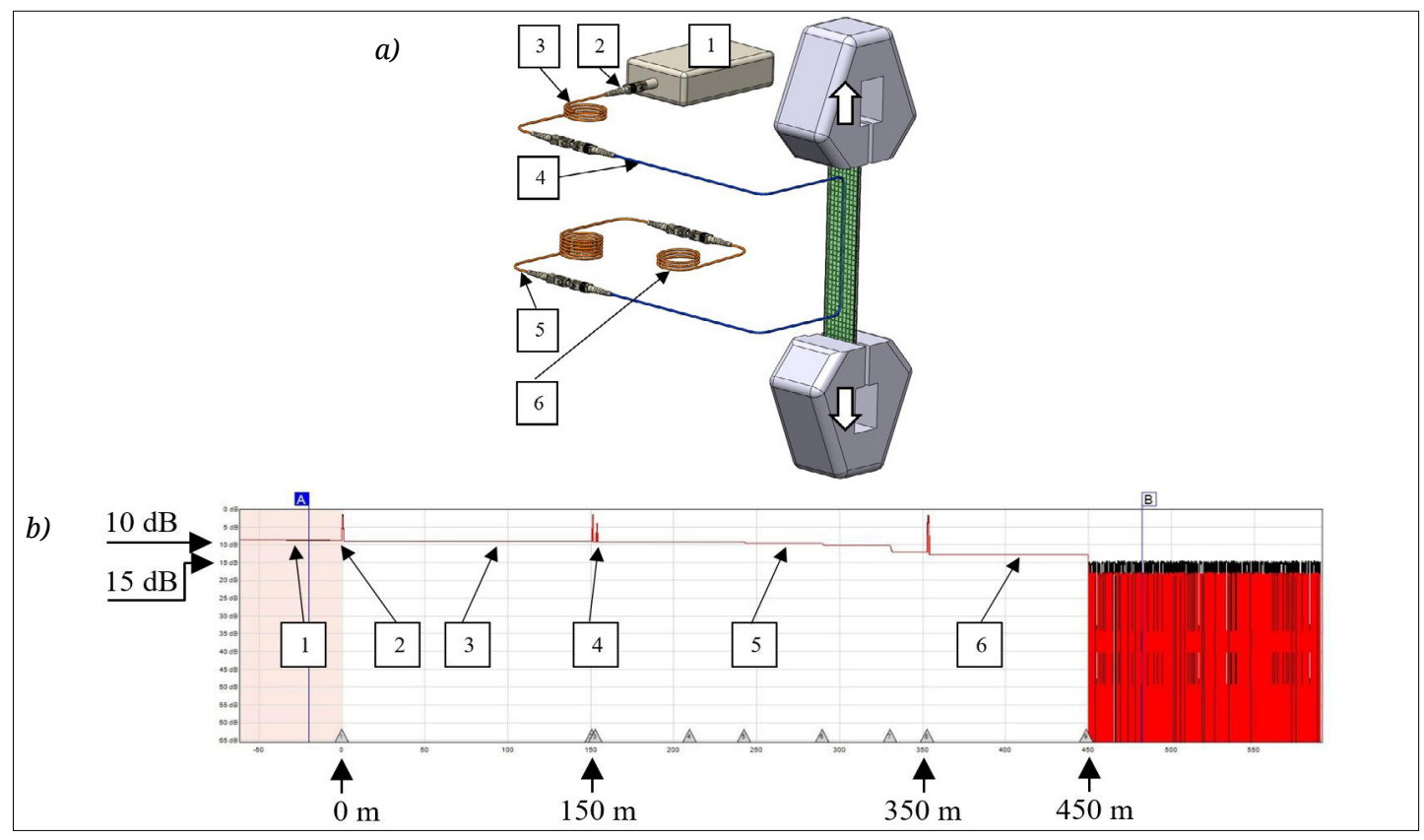

Figure 9. OTDR measurement layout (a) and the values measured with the OTDR on the unloaded specimen (b) (1 - OTDR, 2 - optical connector, 3 - $150 \mathrm{~m}$ long ballast fiber, 4 - $3 \mathrm{~m}$ long optical fiber with a $140 \mathrm{~mm}$ long section built into the composite specimen, 5 - $200 \mathrm{~m}$ long optical fiber, 6 - $100 \mathrm{~m}$ long optical fiber wound with a small radius to eliminate reflection). 


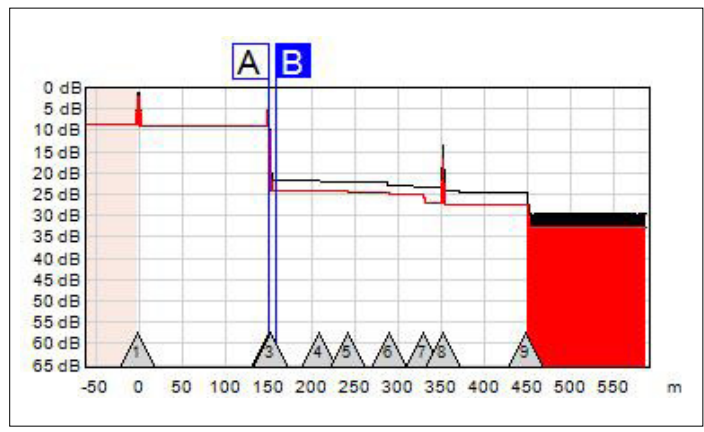

Figure 10. The software of the OTDR identifies the different attenuation-points with numbers marked at the bottom of the figure.

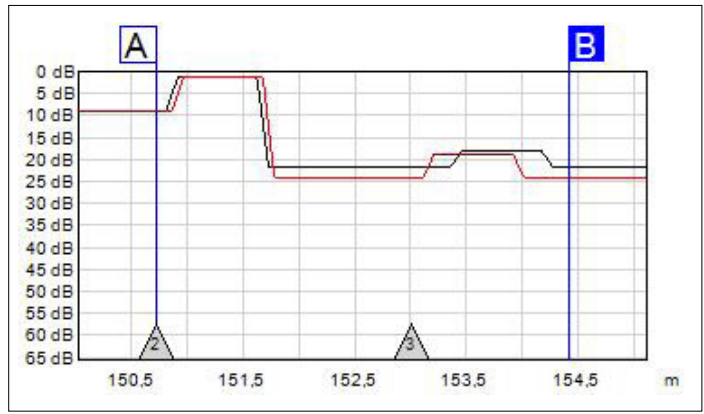

Figure 11. Diagram of OTDR measurement at the attenuation drop measured on the loaded specimen, section $A-B$ of Figure 10 enlarged.

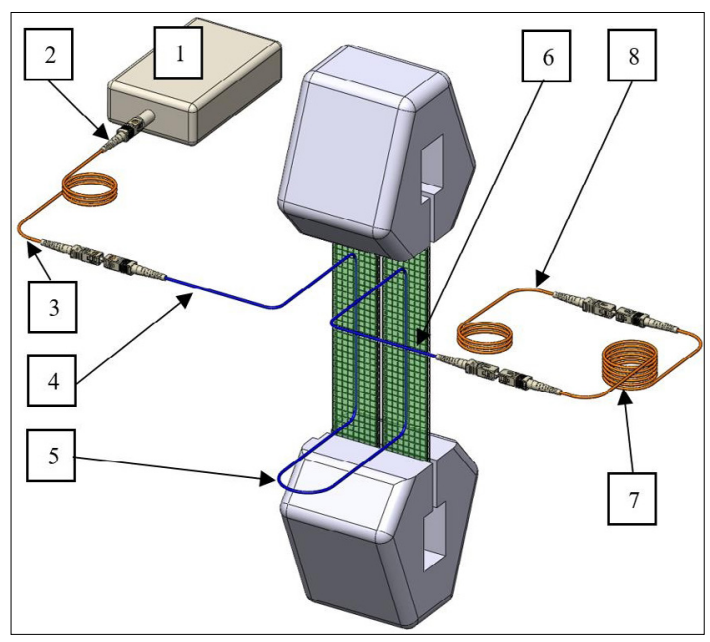

Figure 12. Measurement layout with two clamped test pieces (1 - OTDR instrument, 2 - optical connector, 3 - $150 \mathrm{~m}$ long ballast fiber, 4 $1.5 \mathrm{~m}$ long fiber section leading to the test piece, 5 - 13 m fiber section connecting the test pieces), $6-1.5 \mathrm{~m}$ long fiber section exiting the specimen, 7 - $200 \mathrm{~m}$ long optical fiber, 8 - $100 \mathrm{~m}$ long fiber wound with a small radius to eliminate reflection).

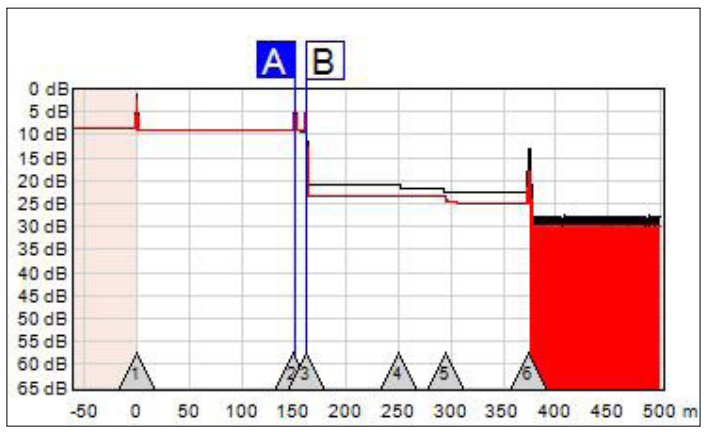

Figure 13. OTDR measurement graph of the fiber loaded in the two gripped specimens.

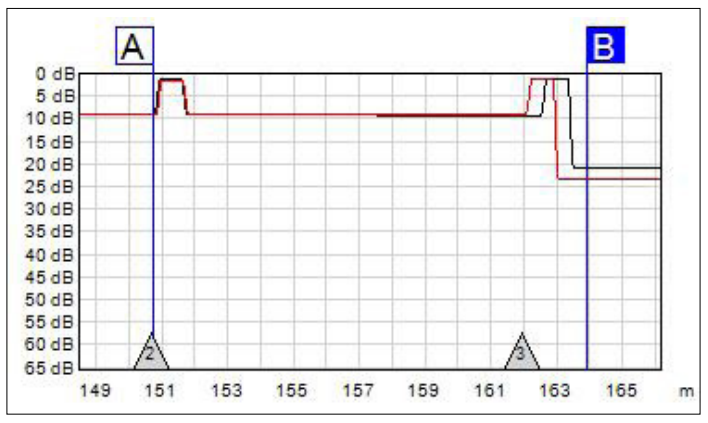

Figure 14. A detail of the OTDR measurement graph of the fiber loaded in the two gripped specimens.

Only two protruding peaks appear on the graph drawn by the OTDR software, and they do not show the same attenuation change either. The nature of the instrument developed for optical networks is well demonstrated in this measurement. In this case, the instrument was no longer able to distinguish the mechanical optical connectors, they were no longer displayed on the graph, and the software was not able to properly evaluate the attenuation change measured at each point. The instrument measured $15.6 \mathrm{~dB}$ attenuation at $1310 \mathrm{~nm}$ at the location marked with signal line "A", but did not indicate this on the graph. At this length, in reality, one of the loaded specimens had a built-in optical fiber section and the ODTR regarded the $15.6 \mathrm{~dB}$ attenuation change as caused by the tensile load on the specimen. At mark "B", the device measured $14.3 \mathrm{~dB}$ of attenuation at $1310 \mathrm{~nm}$ and at $162.0 \mathrm{~m}$, and also showed this on the graph.

The results showed that the OTDR is able to detect and distinguish several loaded sections of a single optical fiber, it can measure their attenuation changes and their location with an accuracy of a few decimeters. However, these sections may 
be incorrectly identified by the software, so when the results are evaluated, it needs to be considered that the software was developed specifically to assess the quality of optical networks.

\section{Conclusions}

Although originally the optical power meter and the OTDR are used to check the quality of telecommunication optical networks, for a more general purpose, the method presented may be suitable for in-situ condition monitoring of polymer matrix composite materials and detect the presence of deformation prior to critical failure. The cost-effectiveness of the method is ensured by the devices used, since both glass optical fibers and the optical power meter are an easily accessible device nowadays.

Our results show that the attenuation of a single-mode optical fiber built into a polymer composite changes as a function of strain. After the non-damaging load ceases, the attenuation of the built-in optical fiber returns to its initial, unloaded value. The method is able to indicate the strain of the composite structure above $1 \%$ before it reaches a strain causing damage to the structure. Knowing the loaded length of the section of the built-in optical fiber, the strain state of the composite structure can be categorized on the basis of its attenuation change: proper, or requiring additional testing. In the case of a built-in optical fiber section of a given length, the maximum attenuation change at which the strain of the composite does not exceed $1 \%$ can be determined; in the case of a larger attenuation change, the strain of the composite should be tested by additional measurement. The reason for the attenuation change is that the optical fiber is adhesively bonded to the matrix of the composite, and thus the optical fiber also deforms as the composite deforms, which reduces the light transmittance of the fiber, i.e., increases its attenuation.

We have shown that the attenuation change due to the deformation of the optical fiber built into a composite specimen can also be identified with an OTDR. The OTDR is not suitable for in-situ analysis, but may be a suitable complement to measurement with an optical power meter. With the help of the OTDR, the location (or locations) of the deformation causing the large attenuation change within the optical fiber can be determined with an accuracy of half a meter. The differently deformed locations can be separated from each other if there is a suitable length unloaded section $(\sim 3 \mathrm{~m})$ between them, otherwise the measuring instrument will not be able to separate them.

\section{Acknowledgments}

This work was supported by the National Research, Development and Innovation Office, Hungary (NKFIH) [OTKA K 116070 and K120592; NVKP_161-2016-0046; and 2017-2.2.4-TÉT-AT]; the Higher Education Excellence Program of the Ministry of Human Capacities, Hungary in the framework of the Nanotechnology research area of the Budapest University of Technology and Economics, Hungary [BME FIKP-NAT]; and the National Research, Development and Innovation Fund, Hungary [TUDFO/51757/2019-ITM, Thematic Excellence Program].

The authors wish to thank András Nagy, Péter Dobos and Zsolt Szabó (ATL Kft.) for their help in performing the measurements.

\section{References}

[1] Kovács L., Romhány G.: Derivation of Ply Specific Stiffness Parameters of Fiber Reinforced Polymer Laminates via Inverse Solution of Classical Laminate Theory. Periodica Polytechnica Mechanical Engineering, 62. (2018) 158-164.

https://doi.org/10.3311/PPme.11846

[2] Maamar D., Zenasni R.: Optimization of Safety Factor by Genetic Algorithm of Circular Notched Carbon / Epoxy Laminate at Low Velocity Impact. Periodica Polytechnica Mechanical Engineering, 62. (2018) 218-225.

https://doi.org/10.3311/PPme.12041

[3] Sethy D., Makireddi S., Varghese F. V., Balasubramaniam K.: Piezoresistive behaviour of graphene nanoplatelet (GNP)/PMMA spray coated sensors on a polymer matrix composite beam. Express Polymer Letters, 13/11. (2019) 1018-1025.

https://doi.org/10.3144/expresspolymlett.2019.88

[4] Krawczak P.: Polymer composites: Evolve towards multifunctionality or perish. Express Polymer Letters, 13/9. (2019) 771.

https://doi.org/10.3144/expresspolymlett.2019.65

[5] Konstantopoulos S., Fauster E., Schledjewski R.: Monitoring the production of FRP composites: A review of in-line sensing methods. Express Polymer Letters, 8/11. (2014) 823-840.

https://doi.org/10.3144/expresspolymlett.2014.84

[6] Glisic B., Inaudi D.: Fibre optic methods for structural healt monitoring. John Wiley \& Sons Ltd., New York, 2007.

[7] Grattan K. T. V., Meggitt B. T.: Optical fiber sensor technology. Springer Science+Business Media, B.V, Dordrecht, 1995.

[8] MSZ 9620-1:1990: Fénytechnikai terminológia. A sugárzás alapfogalmai, mennyiségei és egységei.

[9] Elliott B., Gilmore M.: Fiber Optic cabling. Newnes, Oxford, 2002.

[10] Chinpon A., Thamaphat K., Hansuparnusorn M., Limsuwan P.: A force measurement method using 
the optical fibre beam. Procedia Engineering, 32. (2012) 989-993.

https://doi.org/10.1016/j.proeng.2012.02.043

[11] Luo F., Liu J., Ma N., Morse T. F.: Fiber optic microbend sensor for distributed sensing application in the structural strain monitoring. Sensors and Actuators, A: Physical, 75/1. (1999) 41-44. https://doi.org/10.1016/S0924-4247(99)00043-6

[12] Hu H.-F., Sun S.-J., Lv R.-Q., Zhao Y.: Design and experiment of an optical fiber micro bend sensor for respiration monitoring. Sensors and Actuators, A: Physical, 251. (2016) 126-133. https://doi.org/10.1016/j.sna.2016.10.013

[13] Crane R. M., Gagorik J.: Fiber optics for a damage assessment system for fiber reinforced plastic composite structures. In: Thompson D.O., Chimenti D.E. (eds) Review of Progress in Quantitative Nondestructive Evaluation. 28. (1984) 1419-1430.

https://doi.org/10.1007/978-1-4613-3706-5_94
[14] Glossop N. D. W., Dubois S., Tsaw W., Leblanc M., Lymer J., Measures R. M., Tennyson R. C.: Optical fibre damage detection for an aircraft composite leading edge. Composites, 21/1. (1990) 71-80. https://doi.org/10.1016/0010-4361(90)90100-B

[15] LeBlanc M., Measures R. M.: Impact damage assessment in composite materials with embedded fibre-optic sensors. Composites Engineering, 2/5-7. (1992) 573-596. https://doi.org/10.1016/0961-9526(92)90044-7

[16] Hegedüs G., Czigány T.: Developing a glass fibre sensor for polymer technology applications. Institute of Physics (IOP) Conference Series: Materials Science and Engineering, 426. (2018) 012015. https://doi.org/10.1088/1757-899X/426/1/012015

[17] Hegedüs G., Czigány T.: Analysis of the applicability of optical fibers as sensors for the structural health monitoring of polymer composites: the relationship between attenuation and the deformation of the fiber. Sensors and Actuators A: Physical, 272. (2018) 206-211.

https://doi.org/10.1016/j.sna.2018.01.039 